\title{
Monosaccharides and Analogues from Simple Achiral Unsaturated Compounds
}

\author{
Antonio J. Moreno-Vargas*, Ana T. Carmona, Elena Moreno-Clavijo, and Inmaculada Robina
}

\begin{abstract}
We present herein a selection of ingenious methods that have been developed to convert inexpensive furan, pyrrole and unsaturated hydrocarbons into enantiomerically enriched monosaccharides and analogues of biological interest.
\end{abstract}

Keywords: Cycloadditions · Furan · Iminoalditols · Monosaccharides P Polyenes · Pyrrole

\section{Cycloadditions of Furans and Pyrroles}

The synthesis of carbohydrates and analogues from 7-oxabicyclo[2.2.1]hept-2enes as starting materials was pioneered by $\mathrm{Just}^{[1]}$ and developed extensively by Vogel's group. 1-Cyanovinyl (1'S)-camphanate adds to furan in the presence of $\mathrm{ZnI}_{2}$ as catalyst to give a mixture of diastereomeric Diels-Alder adducts, from which adduct 1 can be isolated pure by crystallization. Starting from (1R)-camphanic acid, large quantities of pure adduct 2 were prepared.[2] Enantiomerically pure 7-oxanorbornenyl derivatives $\mathbf{1}$ and $\mathbf{2}$ and their products of saponification, ketones (+)-3 and (-)-3, are named 'naked sugars' as they are chirons like those derived from natural hexoses. They are also homochirallike sugars but with three unsubstituted (naked) carbon centers. Their substitution following highly stereoselective methods gives polysubstituted 7-oxabicyclo[2.2.1] heptane-2-ones that can be regioselectively oxidized into different uronolactones 4 , $\mathbf{5}$ and $\mathbf{6}$ which are precursors of D-ribose derivative 7, D-allose and L-talose. ${ }^{[3]}$ Starting from 2, L-allose and D-talose were also similarly prepared[4] (Scheme 1).
${ }^{*}$ Correspondence: Dr. A. J. Moreno-Vargas Department of Organic Chemistry

Faculty of Chemistry

University of Seville

Prof. Garcia González, 1, Seville, Spain

E-mail: ajmoreno@us.es

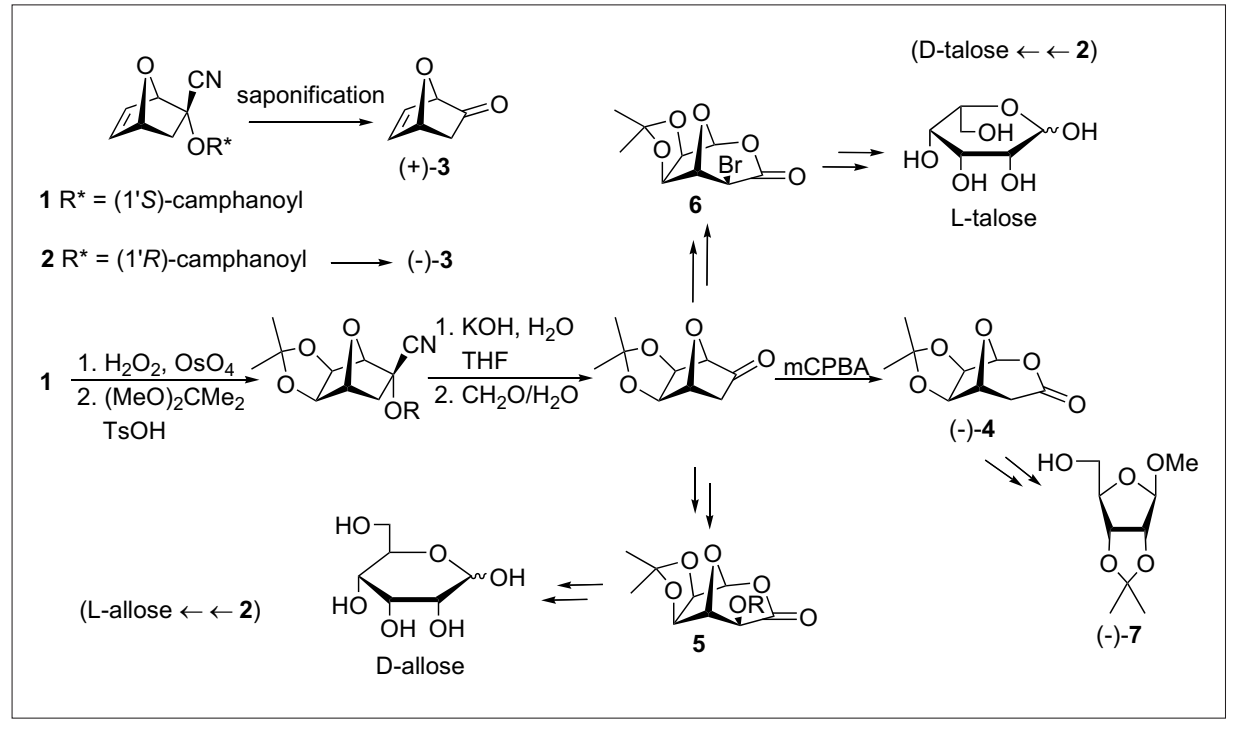

Scheme 1. Use of 'first-generation naked sugars'.

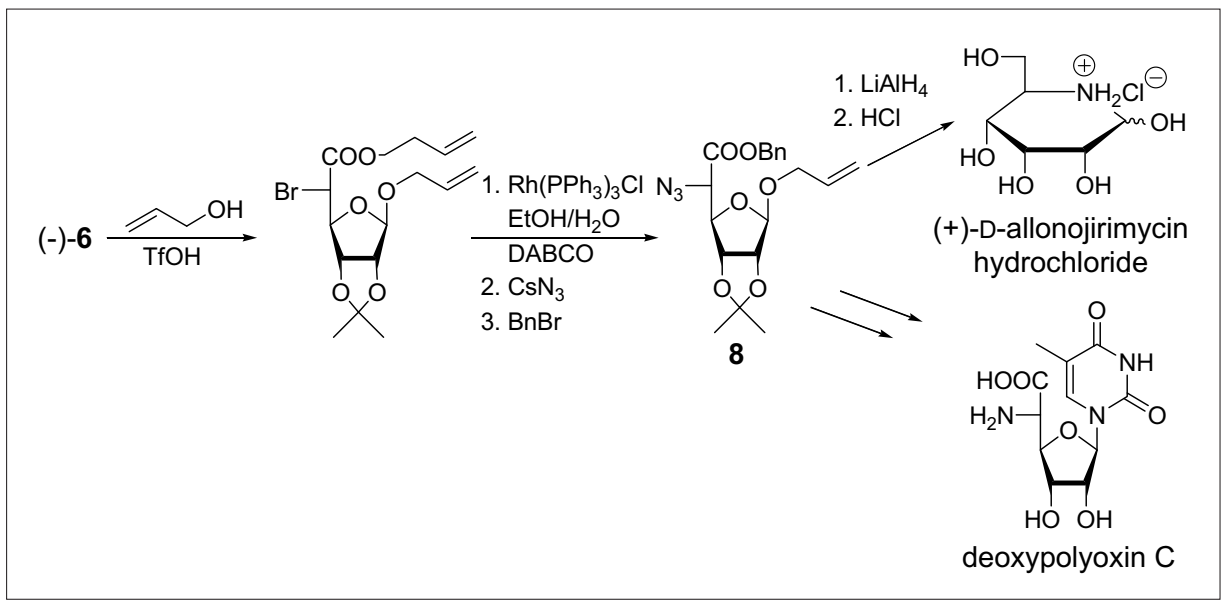

Scheme 2. Total synthesis of deoxypolyoxin $C$ and of (+)-D-allonojirimycin.

The 'naked sugar' methodology has been also used for the synthesis of deoxypolyoxin C (Scheme 2). The $\alpha$-bromouronolactone (-)-6 gives an allyl uronic ester on treatment with allyl alcohol and triflic acid that was converted into azidoderivative $\mathbf{8}$. Compound $\mathbf{8}$ could be transformed into deoxypolyoxin C. ${ }^{[5]}$ It also permitted the first synthesis of (+)-D-allonojirimycin (Scheme 2). ${ }^{[6]}$ L-Daunosamine ${ }^{[7]}$ was also obtained from chiron 1. ${ }^{[8]}$ The "naked sugars' have been converted into long-chain sugars and C-disaccharides, ${ }^{[9]}$ castanospermine and derivatives, ${ }^{[10]}$ and to the 
first examples of polyhydroxylated indolizidines $^{[11]}$ and quinolizidines. ${ }^{[12]}$

Hoffmann and co-workers have developed the synthesis of homochiral 2,6-anhydroheptitols from 8-oxabicyclo[3.2.1] octan-3-one. [13] Enantiomerically pure 3-oxo-8-oxabicyclo[3.2.1] octyl-2-yl derivatives were obtained by $[4+3]$ addition of furan with chiral 1,2-dioxyallyl cation engendered in situ by acid-catalyzed heterolysis of enantiomerically pure mixed acetals derived from 1,1-dimethoxyacetone and enantiomerically pure secondary benzyl alcohols. ${ }^{[14]}$ Adduct (-)-9 was obtained in this manner. This compound was enolized regioselectively and oxidized with mCPBA giving, after esterification, pivalate 10 that was easily converted into anhydroheptitol 11 (Scheme 3).

Vogel and co-workers have also extended the 'naked sugar' methodology to the synthesis of further products of interest, such as dideoxyiminoalditols and polyhydroxylated prolines ('aza naked

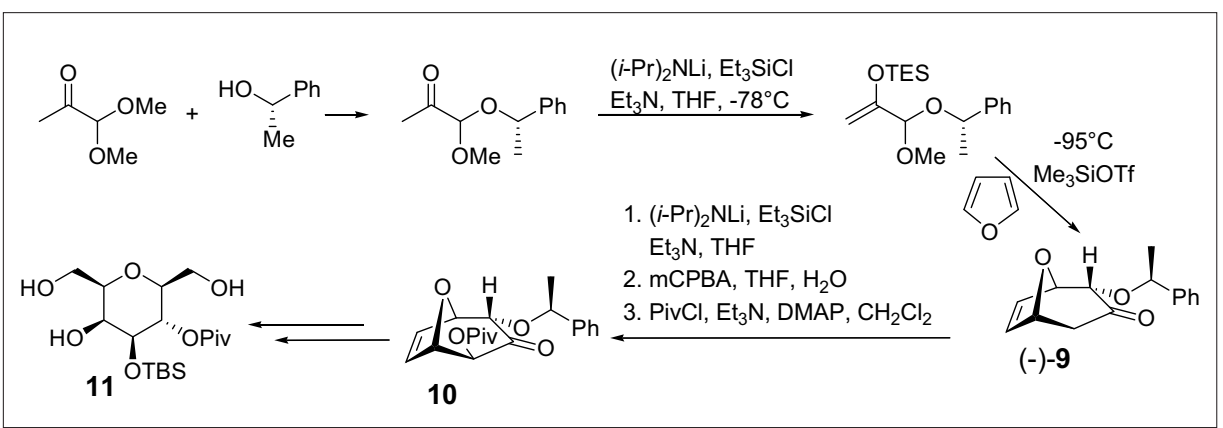

Scheme 3. Hoffmann's asymmetric [4+3]cycloaddition of furan: total synthesis of 2,6-anhydroheptitols.

sugar' methodology). The synthesis of the aza-analogue of compound 3, 7-azabicyclo[2.2.1]hept-5-en-2-one 12, was reported in $1999^{[15]}$ by Trudell et al. in the racemic form, starting from $N$-Boc-pyrrole and 2-bromethynyl $p$-tolyl sulfone. This synthesis was later improved[16] (Scheme 4). The enantiomerically pure forms of $\mathbf{1 2}$ were recently reported.[17]
Other enantiomerically pure 7-azabicyclo[2.2.1]heptane analogues, such as compounds (-)-15, (+)-16 ${ }^{[18]}$ and (+)-17[19] and their corresponding enantiomers, were also reported by Vogel's group (Scheme 5). Compounds (-)-15 and (+)-16 and their corresponding enantiomers were successfully transformed into the iminosugar $\mathbf{1 8}$ and its enantiomer, respectively, which

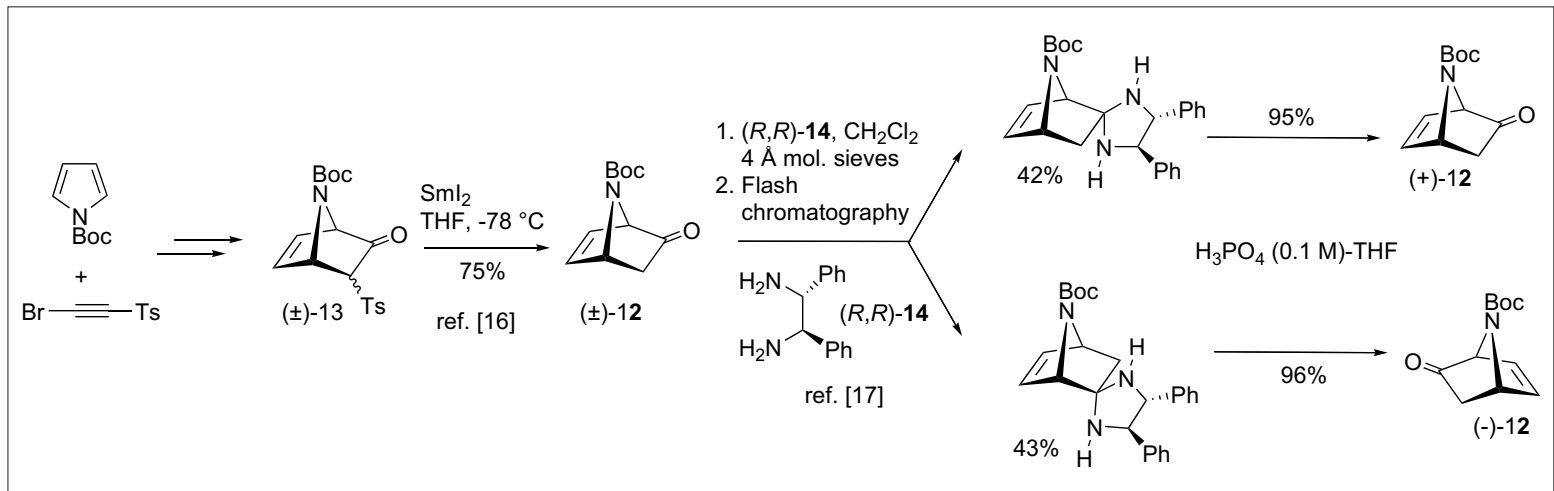

Scheme 4. Synthesis of enantiomerically pure 7-azabicyclo[2.2.1] heptan-2-ones.

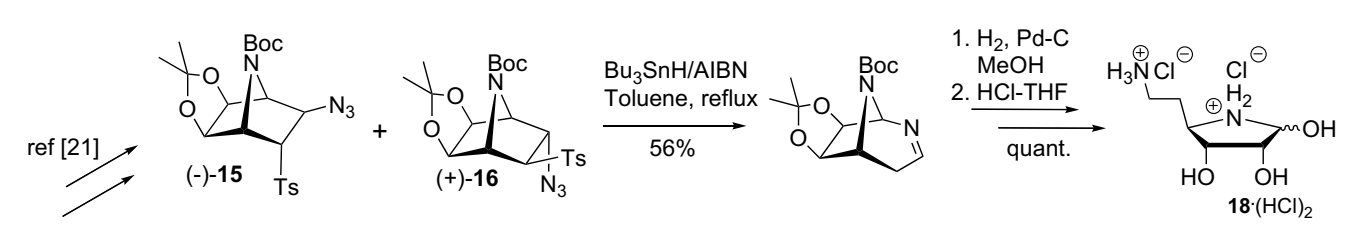

(土)-13

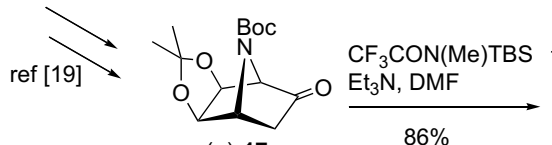
(+)-17

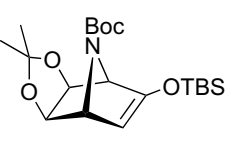

$\underset{88 \%}{\stackrel{\text { 2. } \mathrm{NaBH}_{4}}{\longrightarrow}}$<smiles>CC(CO)CO</smiles>

$\mathrm{Boc} \mathrm{COOH}$<smiles>CCC1C2CN3CCOC(C3)C1O2</smiles>

$(-)-19$

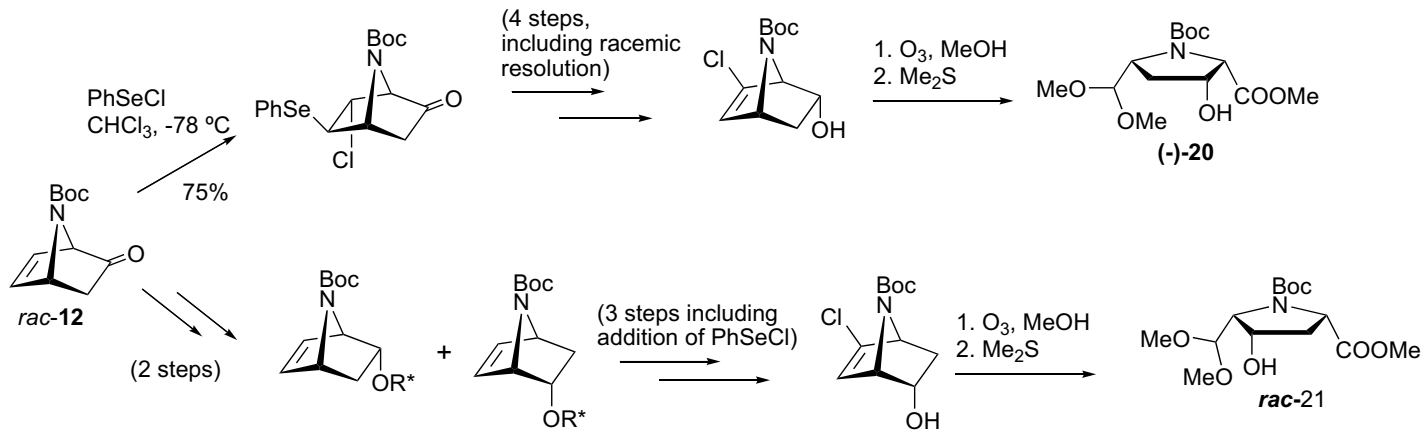

$\mathrm{R}^{*}=$ camphanoyl

Scheme 5. 7-Azabicycloheptanes as intermediates for the synthesis of dideoxyiminosugars and hydroxylated proline derivatives. 
showed strong competitive inhibition towards $\alpha$-mannosidases.[20] The key step of this transformation implies a novel rearrangement on the bicyclic system through aminyl radicals. ${ }^{[21]}$ Ketones $\mathbf{1 7}$ and $\mathbf{1 2}$ were transformed into polyhydroxylated proline derivatives 19,[19] 20 and 21,[22] following the same methodology that was previously employed in the case of oxa-analogues ('naked sugar' chemistry[8a]). These prolines are expected to be useful intermediates for the preparation of new dideoxyiminosugars, such as polyhydroxylated indolizidines and pyrrolizidines, in the search for new glycosidase inhibitors.

\section{Carbohydrates and Analogues from Achiral Polyenes}

An elegant total synthesis of acosamine and of daunosamine was developed at Roche starting from cyclopentadiene. ${ }^{[23]}$ Monomethylation of cyclopentadiene gives 5-methylcyclopentadiene that is hydroborinated asymmetrically with (-)-di3-pinanylborane giving (S)-alcohol 22. Epoxidation syn with respect to the homoallylic alcohol provides $\mathbf{2 3}$, which is oxidized into ketone 24. Baeyer-Villiger oxidation of $\mathbf{2 4}$ is regioselective and leads to lactone 25. This compound was then transformed into methyl- $\alpha$-acosaminide and daunosamine $\cdot \mathrm{HCl}$ (Scheme 6).

Johnson and co-workers reported a total synthesis of 1,3-dideoxynojirimycin starting from cyclopentadiene. [24] Photooxidation of cyclopentadiene and reductive work-up with thiourea generates ciscyclopent-2-ene-1,4-diol. Its enzymatic enantioselective monoacylation, silylation and subsequent treatment with $\mathrm{KOH}$ and oxidation, gave enantiomerically pure enone 26 ${ }^{[25]}$ which was transformed into 27 and (+)-28 as depicted in Scheme 7. A similar approach converted enantiomerically pure $(2 R, 3 R)-2,3$-isopropylidenedioxycyclopent-4-en-1-one derived from cyclopentadiene $^{[26]}$ into (-)-1-deoxymannonojirimycin and (-)-1-deoxytalonojirimycin (1,5-dideoxy-1,5-imino-D-talitol). [27] Enone 26 was converted to $(2 R, 3 S)-2,3$ bis[(tert-butyl)dimethylsilyloxy]cyclopent-4-en-1-one and then to (+)-1-deoxynojirimycin. ${ }^{[28]}$

Dioxygenases, present in the blocked mutants of the soil bacterium Pseudomonas putida, degrades benzene and its derivatives into cyclohexa-3,5-diene-1,2-diols. With chlorobenzene, diol $\mathbf{2 9}$ is obtained with $>99 \%$ ee . This compound is converted in a few chemical steps into several sugars and derivatives ${ }^{[29]}$ such as L-erythrose, $\mathrm{KDN},{ }^{[30]}$ (-)-Neu-5-Ac ${ }^{[31]}$ and Vitamin $\mathrm{C}^{[32]}$ (Scheme 8).

When applied to penta-1,4-diene, the Sharpless asymmetric dihydroxyl-

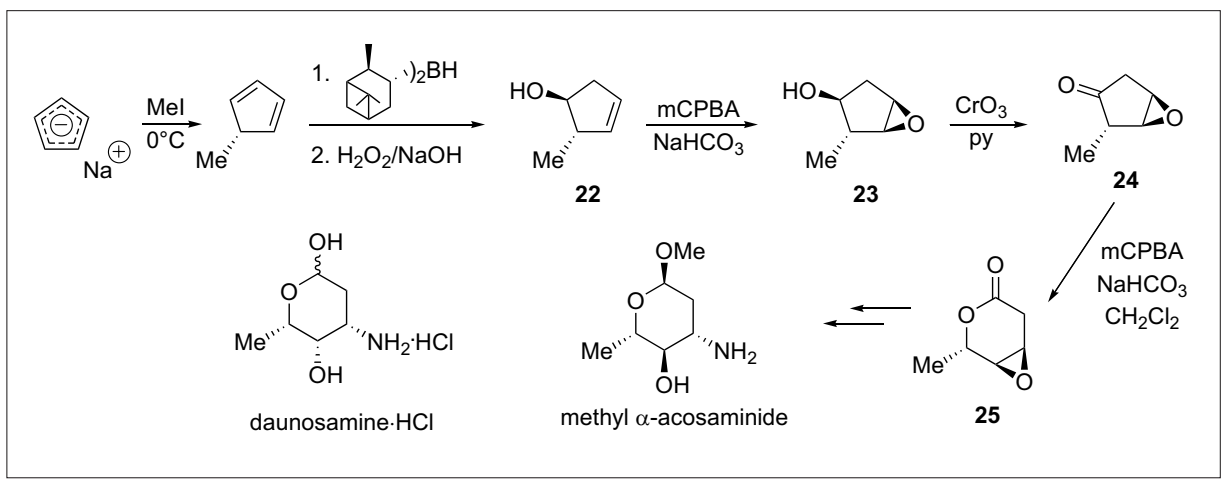

Scheme 6. Roche's synthesis of $\alpha$-acosamine and daunosamine.

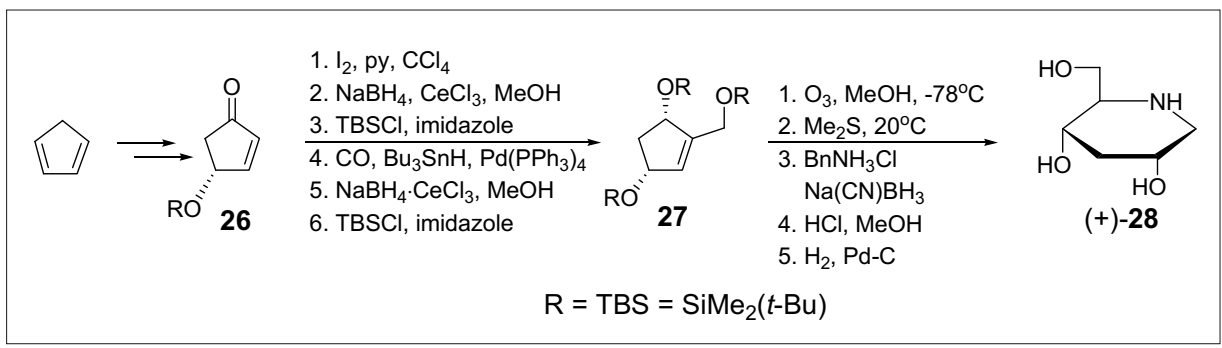

Scheme 7. Johnson's synthesis of 1,3-dideoxynojirimycin.

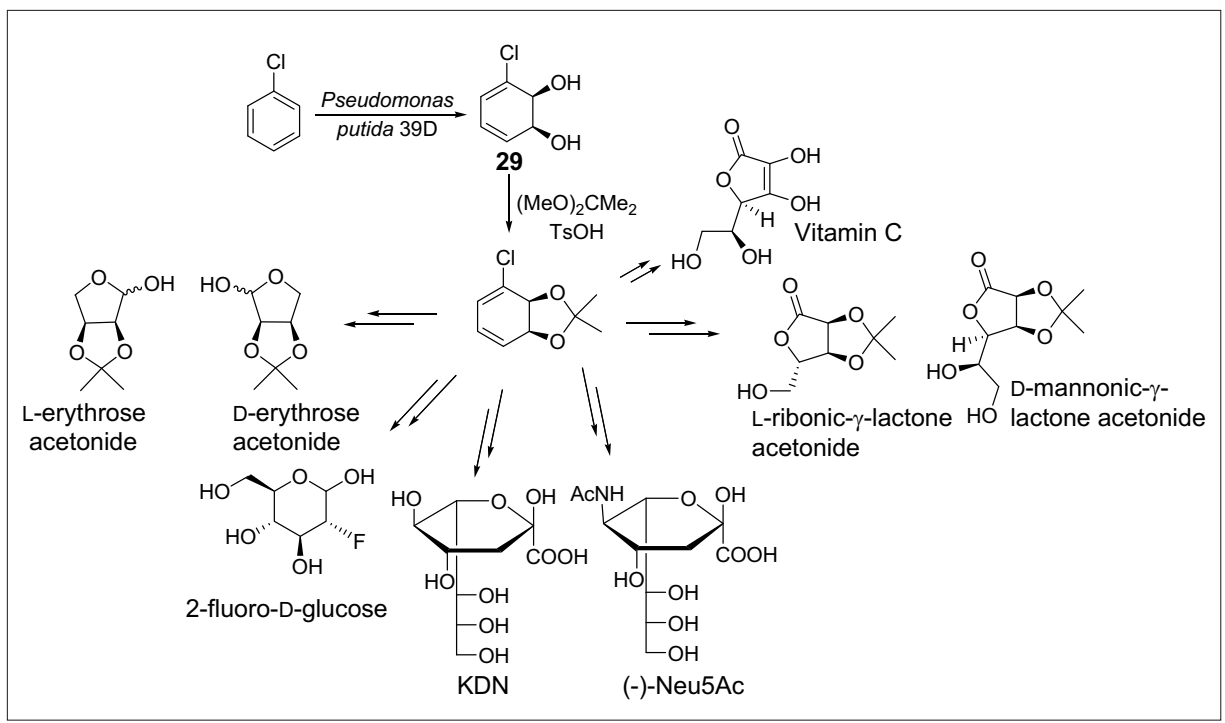

Scheme 8. Hudlicky's syntheses of tetrose, pentose and hexose derivatives and Banwell's syntheses of KDN, Neu5Ac and Vitamin C.

ation forms a $1: 1$ mixture of $(2 S, 4 S)$ - and $(2 S, 4 R)$-penta-1,2,4,5-tetrols, $\mathbf{3 0}$ and $\mathbf{3 1}$ (Scheme 9), which can be converted to diepoxides $\mathbf{3 2}$ and $\mathbf{3 3}$, respectively. ${ }^{[33]}$ The former was converted into dideoxypentitol and -thiopentitol. A stereo- and enantioselective synthesis of $\mathbf{3 2}$ is possible starting from 1,5-dichloropenta-2,4-diene applying Noyori's asymmetric hydrogenation. ${ }^{[34]}$

\section{Desymmetrization of meso Dienols}

Katsuki-Sharpless desymmetrization of penta-1,4-dien-3-ol (34) gives the mono- epoxide 35 which can be converted into 1,4-dideoxy-1,4-imino-D-lyxitol $\mathbf{3 6}$ (Scheme 10).[35] Similarly, Schreiber and co-workers[36] have obtained (+)-KDO from the diallyl alcohol 37 (Scheme 11).

\section{Kinetic Resolution of Racemic Allylic Alcohols}

The Katsuki-Sharpless asymmetric epoxidation of racemic diol $( \pm)-38$ gave, after chromatographic separation, the erythro-epoxide (+)-39 which was further transformed into D-olivose (Scheme 12). Asymmetric epoxidation of the kinetically resolved dienol (-)-40 gave the cor- 
responding epoxide $(75 \%)$ that could be transformed into D-digitoxose. ${ }^{[37]}$ In a similar manner (+)-oliose, (+)-cymarose, ${ }^{[38]}$ D- and L-chalcose ${ }^{[39]}$ were also prepared. Application of the Katsuki-Sharpless enantioselective epoxidation to racemic mono$O$-benzylated divinylglycol allowed the preparation of enantiomerically pure L-lyxo and D-lyxo-pentoses and analogues. ${ }^{[40]}$

\section{Enantioselective Sharpless Dihydroxylation and Aminohydroxylation}

This is an extremely powerful method for the synthesis of monosaccharides and selected examples of application are collected in this section. For instance, tetritol and tetrose derivatives are obtained readily from asymmetric dihydroxylation of $(E)$ but-2-ene-1,4-diol, ${ }^{[41]}$ and 4-deoxy D- and L-threose are derived from benzene-1,2dimethyl acetal of $(E)$-crotonaldehyde. In a similar way, 2-deoxyxylofuranosides are obtained from 5-[(tert-butyldiphenylsilyl) oxy]-(E)-pent-3-enal.[42] Asymmetric dihydroxylation of 2-vinylfuran (41) gives diol (+)-42, which after oxidation with $m$-chloroperbenzoic acid and water elimination furnished (+)-isolevoglucosenone (Scheme 13). This compound can be isomerized into (-)-levoglucosenone. The Lhexose derivative (-)-isolevoglucosenone is obtained with the same ease. ${ }^{[43]}$

Starting from furfural and by applying the same route, D- and L-mannose, D- and L-gulose, D- and L-talose ${ }^{[44]}$ and 2-deoxy and 2,3-dideoxyhexoses ${ }^{[45]}$ were obtained.

The Sharpless asymmetric aminohydroxylation $^{[46]}$ of 2-vinylfuran $\mathbf{4 3}$ gives aminoalcohol 44, that was converted into the $\beta$-hydroxyfurylamine derivative 45 , ${ }^{47]}$ useful building block for the synthesis of various biologically important compounds, including 1,5-dideoxy-1,5-iminoalditols (Scheme 14). A less regioselective, but shorter way to $\mathbf{4 5}$ is the direct asymmetric aminohydroxylation of vinylfuran.

Sharpless asymmetric dihydroxylation of ethyl sorbate gives diol 46 regio- and stereoselectively. This compound was transformed in several steps into tosylamide 47 which is then converted into methyl $N$-tosyl- $\alpha$-D-tolyposaminide (-)-48. Alternatively, diol 46 is reacted with $\mathrm{TsN}=\mathrm{C}=\mathrm{O}$ to give 49. Hydrogenation of the alkene moiety and subsequent methanolysis and acidic treatment provides lactone $\mathbf{5 0}$, which was successfully transformed into 4-epi- $N$-tosyl- $\alpha$-D-tolyposaminide (+)-51 (Scheme 15). ${ }^{[48]}$

Lindström and co-workers ${ }^{[49]}$ have also presented an efficient synthesis of five-membered iminoalditols in water that includes asymmetric dihydroxylation and epoxidation steps (Scheme 16).

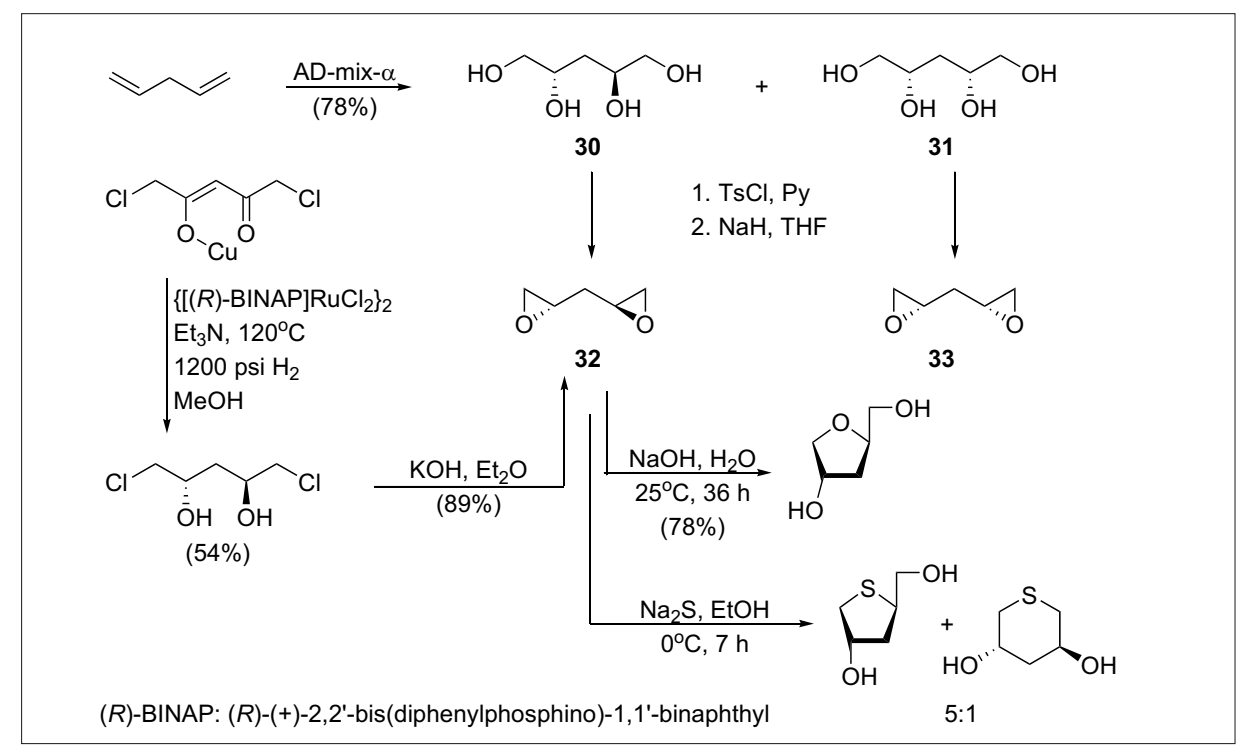

Scheme 9. Conversion of penta-1,4-diene into pentitol derivatives.

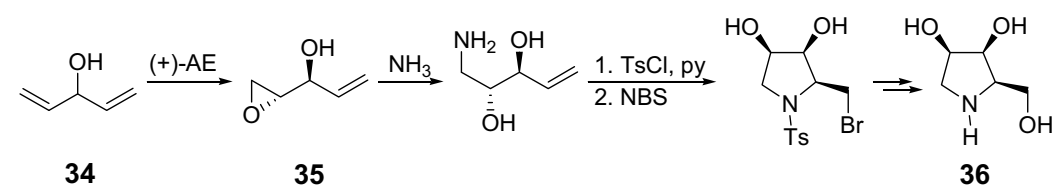

Scheme 10. Jäger's synthesis of 1,4-dideoxy-1,4-iminopentitols.

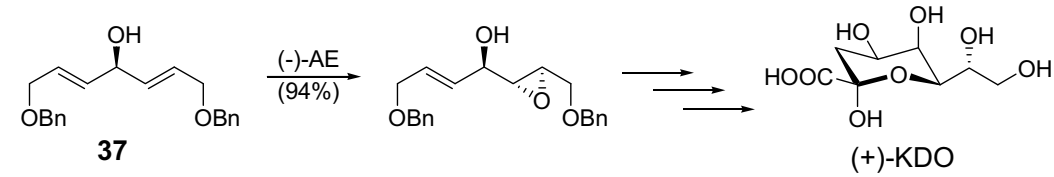

Scheme 11. Schreiber's total synthesis of (+)-KDO.

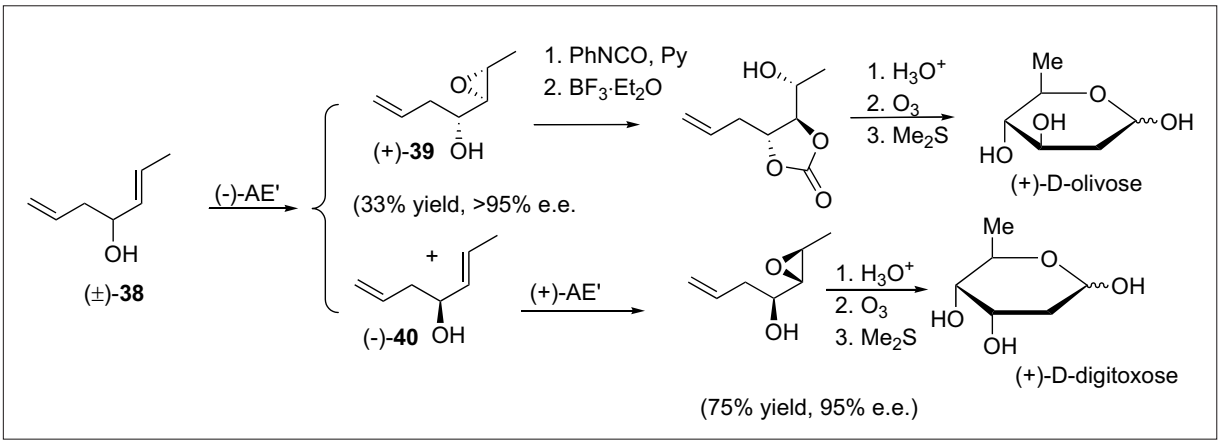

Scheme 12. Total syntheses of 2,6-dideoxyhexoses.

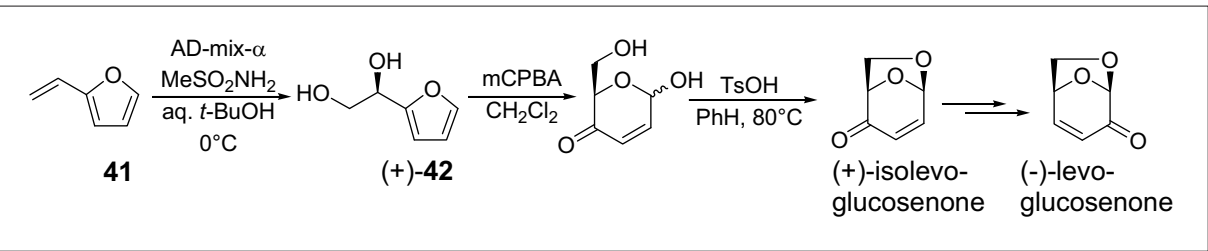

Scheme 13. Total synthesis of (+)-isolevoglucosenone and (-)-levoglucosenone. 


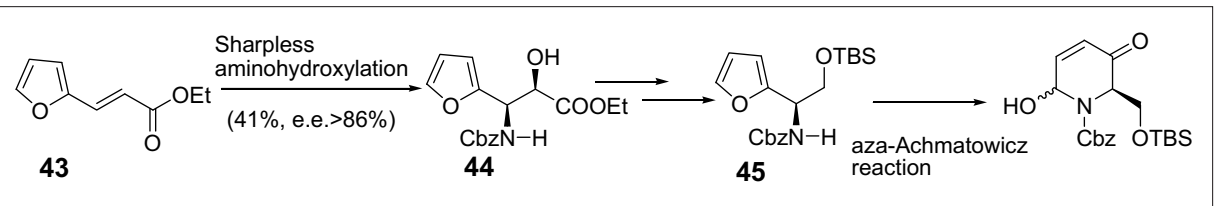

Scheme 14. Application of the Sharpless asymmetric aminohydroxylation and of the aza-Achmatowicz reaction to the synthesis of iminosugars.

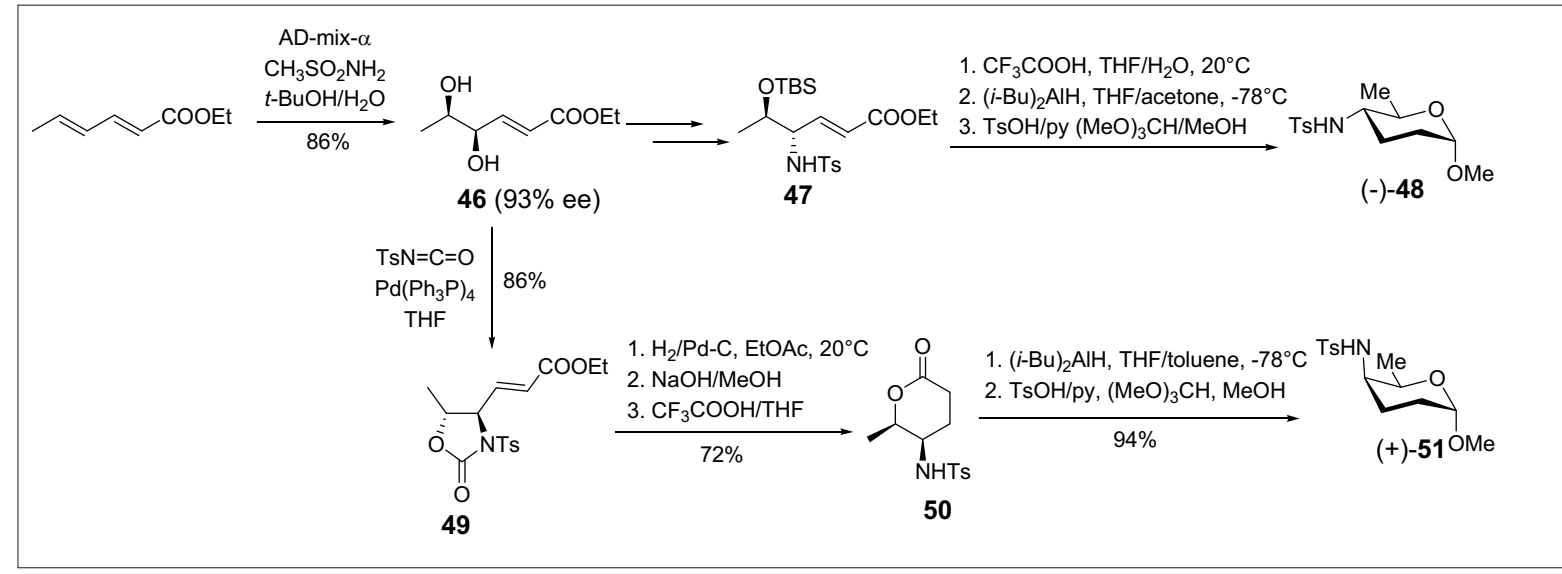

Scheme 15. Synthesis of tolyposaminide derivatives.

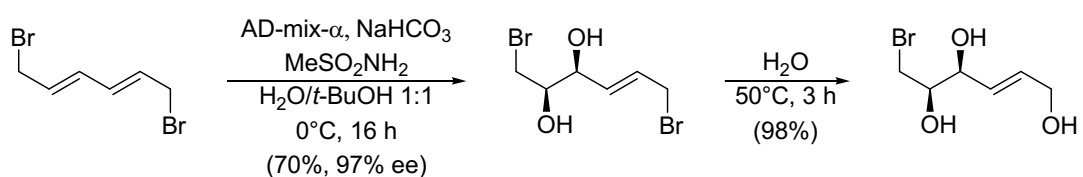

$\mathrm{H}_{2} \mathrm{O}_{2}$ (1.2 equiv.) $\mathrm{H}_{2} \mathrm{O}, 20^{\circ} \mathrm{C}$ $\overrightarrow{\mathrm{K}_{2}\left[\mathrm{~W}_{2} \mathrm{O}_{3}\left(\mathrm{O}_{2}\right)_{4}\left(\mathrm{H}_{2} \mathrm{O}\right)_{2}\right]}$

( 0.02 equiv.)

(99\%, dr 96:4)<smiles>OCC1OC1[C@@H](O)[C@H](O)CBr</smiles>

Scheme 16. Efficient asymmetric synthesis of an azasugar in water

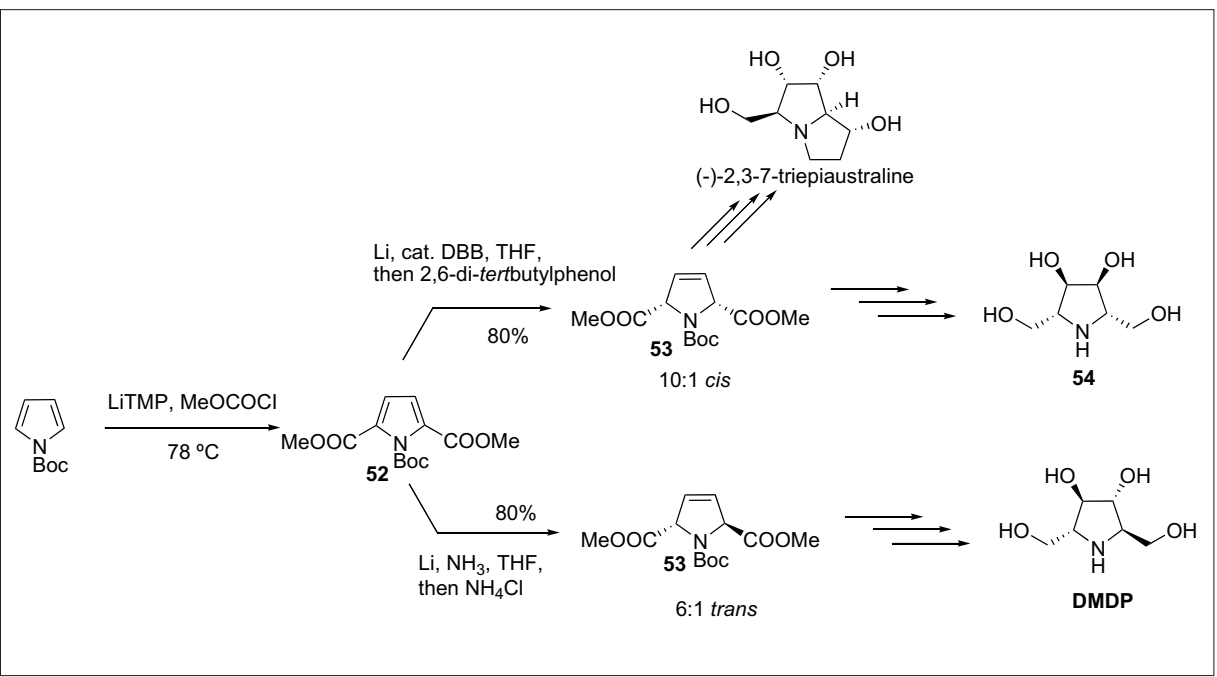

Scheme 17. Partial reduction of pyrrole for the synthesis of DMDP and other iminosugars.

\section{Birch Reduction of Pyrroles}

The Birch reduction of pyrroles with ester functionality at either $\mathrm{C}(2)$ or at both $\mathrm{C}(2)$ and $\mathrm{C}(5)$ is a useful method for the synthesis of iminosugar derivatives that has been broadly exploited by Donohoe's group. ${ }^{[50]} N$-Boc pyrrole was doubly lithi52 (Scheme 17). Pyrrole 52 can be reduced to give the trans isomer of $\mathbf{5 3}$ with good diastereoselectivity, using lithium in ammonia and quenching with ammonium chloride. Reduction under 'ammonia-free'

ated with lithium 2,2,6,6-tetramethylpiperidide (LiTMP), followed by a quench $\underset{10 \% \mathrm{NH}_{3} / \mathrm{H}_{2} \mathrm{O}}{\stackrel{\mathrm{h}(88 \%)}{\longrightarrow}}$

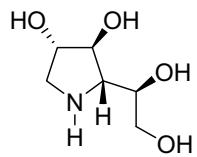

conditions ( $\mathrm{Li}$, catalytic DBB, THF) followed by protonation with 2,6-di-tertbutylphenol gives $c i s-53$ exclusively. These two pyrrolines were successfully transformed (among others) into the natural pyrrolizidine alkaloid (-)-2,3,7-triepiaustraline, ${ }^{[51]}$ into the polyhydroxylated pyrrolidine 54 and into the natural glycosidase inhibitor DMDP. ${ }^{52]}$

\section{Conclusion}

For many years carbohydrates were very difficult synthetic targets because of their complexity arising from their stereochemistry and their multifunctional character. In parallel with the recent revolution in organic synthesis, a large number of complicated and rare monosaccharides have been prepared by total asymmetric synthesis starting from inexpensive and ready available starting materials, including furans recovered from the left-overs of agriculture (biomass) and pyrroles. Methods are available that allow one to reach both enantiomers of any natural or non-natural monosaccharide, including deoxyaminosugars, thiosugars and iminosugars, and this, quite often, in few synthetic steps. Depending on the target, pure chemical procedures can be applied successfully, alone or in combination with chemoenzymatic methods.

\section{Acknowledgements}

We thank the Ministerio de Ciencia e Innovación of Spain (CTQ2008-01565/BQU) and the Junta de Andalucía (FQM 345) for
Received: September 21, 2010

\section{financial support.}

[1] a) G. Just, A. Martel, Tetrahedron Lett. 1973 5, 1517; b) G. Just, K. Grozinger, Tetrahedron Lett. 1974, 4165; c) G. Just, K. Grozinger, Can. 
J. Chem. 1975, 53, 2701; d) G. Just, A. Martel, K. Grozinger, M. Ramjeesingh, Can. J. Chem. 1975, 53, 131; e) G. Just, M. Ramjeesingh, T. J. Liak, Can. J. Chem. 1976, 54, 2940.

[2] a) E. Vieira, P. Vogel, Helv. Chim. Acta 1983, 66, 1865; b) A. Warm, P. Vogel, Helv. Chim. Acta 1987, 70, 690; c) For other enantiomerically enriched 7-oxabicyclo[2.2.1]heptane derivatives, see P. Vogel, J. Cossy, J. Plumet, O. Arjona, Tetrahedron 1999, 55, 13521; c) J. L. Reymond, P. Vogel, Tetrahedron:Asymm. 1990, 1,729 .

[3] G. Arvai, D. Fattori, P. Vogel, Tetrahedron 1992, 48, 10621.

[4] Y. Auberson, P. Vogel, Helv. Chim. Acta 1989, $72,278$.

[5] Y. Auberson, P. Vogel, Tetrahedron 1990, 46, 7019.

[6] Y. Auberson, P. Vogel, Angew. Chem. Int. Ed. Engl. 1989, 28, 1498.

[7] A. Warm, P. Vogel, J. Org. Chem. 1986, 51, 5348.

[8] a) P. Vogel, D. Fattori, F. Gasparini, C. LeDrian, Synlett 1990, 173; b) E. de Guchteneere, D. Fattori, P. Vogel, Tetrahedron 1992, 48, 10603; c) see also J.-M. Durgnat, P. Vogel, Helv. Chim. Acta 1993, 76, 222

[9] a) S. Jeganathan, P. Vogel, J. Org. Chem. 1991, 56, 1133; b) D. P. Neff, Y. Chen, P. Vogel, Helv. Chim. Acta 1991, 74, 508; c) R. M. Bimwala, P. Vogel, J. Org. Chem. 1992, 57, 2076; d) F. Emery, P. Vogel, J. Org. Chem. 1995, 60, 5843; e) R. Ferritto, P. Vogel, Tetrahedron:Asymm. 1994, 5, 2077; f) A. Baudat, P. Vogel, Tetrahedron Lett. 1996, 37, 483; g) J. Cossy, J.-L. Ranaivosata, V. Bellosta, J. Ancerewycz, R. Ferritto, P. Vogel, $J$. Org. Chem. 1995, 60, 835; h) V. Jeanneret, L. Meerpoel, P. Vogel, Tetrahedron Lett. 1997, 38 , 543; i) K. Kraehenbuehl, S. Picasso, P. Vogel, Helv. Chim. Acta 1998, 81, 1439; j) C. Marquis, S. Picasso, P. Vogel, Synthesis 1999, 1441.

[10] J.-L. Reymond, A. A. Pinkerton, P. Vogel, J. Org. Chem. 1991, 56, 2128.

[11] a) Y. Chen, P. Vogel, Tetrahedron Lett. 1992, 33, 4917; b) Y. Chen, P. Vogel, J. Org. Chem. 1994, 59, 2487.

[12] a) C. Schaller, P. Vogel, Synlett 1999, 1219; b) C. Schaller, P. Vogel, Helv. Chim. Acta 2000 , 83, 193.

[13] H. M. R. Hoffmann, R. Dunkel, M. Mentzel, H. Reuter, C. B. W. Stark, Chem. Eur. J. 2001, 7, 4771.

[14] C. B. W. Stark, S. Pierau, R. Wartchow, H. M. R. Hoffmann, Chem. Eur. J. 2000, 6, 684.
[15] C. Zhang, C. J. Ballay II, M. L. Trudell, J. Chem. Soc., Perkin Trans. 1 1999, 675.

[16] Z.-L. Wei, C. George, A. P. Kozikowski, Tetrahedron Lett. 2003, 44, 3847.

[17] A. J. Moreno-Vargas, P. Vogel, Tetrahedron: Asymm. 2003, 14, 3173.

[18] A. J. Moreno-Vargas, C. Schutz, R. Scopelliti, P. Vogel, J. Org. Chem. 2003, 68, 5632.

[19] A. J. Moreno-Vargas, I. Robina, E. Petricci, P. Vogel, J. Org. Chem. 2004, 69, 4487.

[20] a) H. Fiaux, F. Popowycz, S. Favre, C. Schütz, P. Vogel, S. Gerber-Lemaire, L. JuilleratJeanneret, J. Med. Chem. 2005, 48, 4237; b) K. Kraehenbuehl, S. Picasso, P. Vogel, Helv. Chim. Acta 1998, 81, 1439.

[21] A. J. Moreno-Vargas, P. Vogel, Tetrahedron Lett. 2003, 44, 5069.

[22] A. A. Ruggiu, R. Lisek, E. Moreno-Clavijo, A. J. Moreno-Vargas, I. Robina, P. Vogel, Tetrahedron 2010, 66, 7309.

[23] G. Grethe, J. Sereno, T. H. Williams, M. R. Uskokovic, J. Org. Chem. 1983, 48, 5315.

[24] C. R. Johnson, A. Golebiowski, M. P. Braun, H. Sundram, Tetrahedron Lett. 1994, 35, 1833.

[25] C. R. Johnson, M. P. Braun, J. Am. Chem. Soc. 1993, 115,11014

[26] a) C. R. Johnson, T. D. Penning, J. Am. Chem. Soc. 1988, 110, 4726; b) R. J. Parry, K. Haridas, R. De Jong, C. R. Johnson, Tetrahedron Lett. 1990, 31, 7549 .

[27] C. R. Johnson, A. Golebiowski, E. Schoffers, H. Sundram, M. P. Braun, Synlett 1995, 313.

[28] C. R. Johnson, B. M. Nerurkar, A. Golebiowski, H. Sundram, J. L. Esker, Chem. Commun. 1995. 1139.

[29] T. Hudlicky, D. A. Entwistle, K. K. Pitzer, A. J. Thorpe, Chem. Rev. 1996, 96, 1195.

[30] M. Banwell, C. De Savis, K. Watson, Chem Commun. 1998, 1189.

[31] M. Banwell, C. De Savis, K. Watson, J. Chem Soc., Perkin Trans. 1 1998, 2251.

[32] M. Banwell, S. Blakey, G. Harfoot, R. Longmore, J. Chem. Soc., Perkin Trans. 11998 , 3141 .

[33] M. E. Jung, O. Kretschik, J. Org. Chem. 1998, 63, 2975.

[34] S. F. Rychnovsky, G. Griesgaber, S. Zeller, D. J. Skalitzky, J. Org. Chem. 1991, 56, 5161.

[35] V. Jäger, W. Hümmer, Angew. Chem. Int. Ed. Engl. 1990, 29, 1171.

[36] D. S. Smith, Z. Wang, S. L. Schreiber, Tetrahedron 1990, 46, 4793.

[37] a) W. R. Roush, R. J. Brown, J. Org. Chem 1982, 47, 1371; b) W. R. Roush, R. J. Brown,
M. DiMare, J. Org. Chem. 1983, 48, 5083; c) W. R. Roush, J. A. Straub, M. S. Van Nieuwenhze, J. Org. Chem. 1991, 56, 1636.

[38] a) W. R. Roush, R. J. Brown, J. Org. Chem. 1983, 48, 5093; b) K. C. Nicolaou, R. M Rodriguez, H. J. Mitchell, F. L. van Delft, Angew. Chem. Int. Ed. Engl. 1998, 37, 1874.

[39] U. Küfner, R. R. Schmidt, Angew. Chem. Int. Ed. Engl. 1986, 25, 89.

[40] a) R. R. Schmidt, K. Frische, Liebigs Ann. Chem. 1988, 209; b) For other applications, see Y.-M. Xu, W.-S. Zhou, Tetrahedron Lett. 1996, 37, 1461; c) J. A. Marshall, Y. Tang, J. Org. Chem. 1994, 59, 1457; d) V. Jäger, W. Hümmer, Angew. Chem. Int. Ed. Engl. 1990, 29, 1171.

[41] S. Y. Ko, M. Malik, Tetrahedron Lett. 1993, 34, 4675.

[42] M. E. Jung, J. M. Gardiner, Tetrahedron Lett. 1994, 35,6755

[43] T. Taniguchi, H. Ohnishi, K. Ogasawara, Chem. Commun. 1996, 1477.

[44] a) J. M. Harries, M. D. Keranen, G. A. O'Doherty, J. Org. Chem. 1999, 64, 2982 b) see also: J. M. Harris, G. A. O'Doherty, Tetrahedron Lett. 2000, 41, 183.

[45] M. H. Haukaas, G. A. O'Doherty, Org. Lett. 2002, 4, 1771.

[46] G. Li, H.-T. Chang, K. B. Sharpless, Angew. Chem. Int. Ed. Engl. 1996, 35, 451.

[47] M. L. Bushey, M. H. Haukass, G. A. O’Doherty, J. Org. Chem. 1999, 64, 3984.

[48] a) M. H. Haukaas, G. A. O'Doherty, Org. Lett. 2001, 3, 401; b) For further applications of asymmetric dihydroxylation, e.g. S. LemaireAudoire, P. Vogel, Tetrahedron:Asymm. 1999, 10, 1283; Y. Matsushima, J. Kino, Tetrahedron Lett. 2005, 46, 8609.

[49] U. M. Lindström, R. Ding, O. Hidestal, Chem. Commun. 2005, 1773.

[50] a) T. J. Donohoe, R. E. Thomas, Chem. Rec. 2007, 7, 180; b) T. J. Donohoe, M. D. Cheeseman, T. J. C. O'Riordan, J. A. Kershaw, Org. Biomol. Chem. 2008, 6, 3896.

[51] T. J. Donohoe, R. E. Thomas, M. D. Cheeseman, C. L. Rigby, G. Bhalay, I. D. Linney, Org. Lett. 2008, 10, 3615 .

[52] T. J. Donohoe, C. E. Headley, R. P. C. Cousins, A. Cowley, Org. Lett. 2003, 5, 999. 